particular relating to 'Alcohol Misuse/Abuse' and 'Alcohol Dependency'.

Edwards et al (1973) found a prevalence of 3\% for 'problem drinking'; while Mayou \& Hawton (1986) found about 20\% of general hospital in-patients to have 'alcohol problems', More recently, Goddard (1991) has shown that 23\% of men and $8 \%$ of women drink more than the recommended 'sensible' limits of 21/14 units per week respectively. Bearing these indications of a high prevalence in mind, it is interesting to consider the DVLA guideline concerning the definition of 'alcohol misuse/abuse':

"a state which because of consumption of alcohol, causes disturbance of behaviour, related disease of other consequences, likely to cause the patient, his family or society harm now or in the future and which may or may not be associated with dependency. In addition assessment of the alcohol consumption with respect to current national advised guidelines is necessary" (emphasis added).

Thus, a male drinking more than 21 units or a female drinking more than 14 units in a week showing a "disturbance of behaviour" (such as intoxication?) which may cause "harm ... in the future" is in the firing line. The subjective assessment of 'likelihood' determines whether the doctor should advise the patient to inform the DVLA that he or she has an alcohol problem, which will entail revocation or refusal of a licence for "at least one year".

'Alcohol misuse' is effectively defined by the DVLA as 'excessive use'. This guideline is too debatable. It might be fatal if, as a consequence, it were ignored.

DRIVER \& VeHICLE LiCENSING AGency (1993) At a Glance Gutde to the Current Medical Standards of Futness to Drive. Swansea: DVLA.

EDWARDS, G., HAWKer, A., Hensman, C., et al (1973) Alcoholics known or unknown to agencies: epidemiological studles in a London suburb. British Journal of Psychiatry. 123, 169-183.

GODDARD. E. (1991) Drinking in England and Wales in the Late 1980s. London: HMSO.

MAYOU, R. \& HAWTON, K. (1986) Psychlatric disorder in the general hospital. British Journal of Psychiatry, 149, 172 190.

J.C. Hughes and C.C.H. CoOK, Alcohol Treatment Unit, Princess Alexander's Hospital, RAF Wroughton, Swindon, Wiltshtre SN4 OQJ

Sir: I read with interest the article on mental disorder and driving, (Laurie \& Milne, Psychiatric Bulletin, April 1994, 18, 214-216). It addressed the important issue of medical standards of fitness to drive with regard to the Driver and Vehicle Licensing Centre. In my experience, patients have been less concerned about this particular area than the potential effect on their insurance cover if they were to have an accident and it was discovered that they were using psychotropic medication.

I am unaware of any test cases but would be interested to hear from colleagues on their views and also their experiences with insurance companies and patients on medication.

CHRISTINE M. TYRIE, Garlands Hospital, Carlisle, Cumbria CA1 3SX

\section{Refusal of visas}

Sir: It was interesting to read the article 'Do patients who have been on "sections" get refused visas', by Allen \& Allen (Psychiatric Bulletin, April 1994, 18, 216-217).

I worked as a psychiatric registrar in the West Indies and there was a firm belief that the US Embassy tends to refuse visas to patients who have had formal admissions to psychiatric hospitals. It would be interesting to go through the visa application forms completed by these individuals and compare the data with the outcome of how many of them succeed in getting a visa. There may be ethical or policy objections to this kind of survey.

Many countries say that they would not refuse a visa unless there is a written policy stating otherwise, such as Nepal. But even if the real reason to refuse a visa is formal admission to a psychiatric hospital, it may not be officially given as the reason.

Chandrudu Duggirala, Leicester Frith Hospital, Groby Road, Leicester LE3 9QF

\section{Improving psychiatry's image}

Sir: Although the Public Education Committee has been tolling away for the past several years to improve the image of psychiatry by producing the Help is at Hand leaflets, mounting frequent media briefings, producing the careers pack. training members of the College in media activity, promoting the Morris Markowe prize and the Boots prize for the best video on a career in psychiatry, organising a network of regional and public education offices and fielding hundreds of questions every year from the media, with the help of our teams of experts, to say nothing of launching the Defeat Depression Campaign, we are well aware that the image of the psychiatrist is sometimes tarnished, or blurred; it is therefore enormously helpful to have Dr Kwame McKenzie's suggestion that we need an image consultant (Psychiatric Bulletin, April 1994, 18, 231-232). Gosh, if only we had though of that before.

However, there may be light at the end of the tunnel. Nobody presents a better image of the 